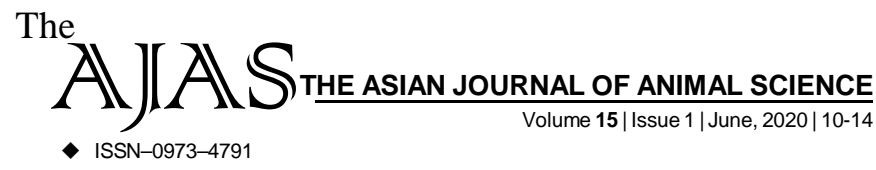

DOI : 10.15740/HAS/TAJAS/15.1/10-14 Visit us | www.researchjournal.co.in

RESEARCH ARTICLE.

\title{
Tenderization of spent japanese quail using ginger extract and sodium bi carbonate
}

\section{Anna Anandh}

Author for Corresponding -

\section{Anna Anandh}

Tamil Nadu Veterinary and Animal Sciences University (TANUVAS), Department of Livestock Products Technology, Veterinary College and Research Institute, Tirunelveli (T.N.) India

Email: drannaanandh@gmail.com
ABSTRACT...... A study was conducted to standardize the method for tenderization of spent Japanese quail (Coturnix coturnix japonica) with ginger extract (GE) and sodium bi carbonate (SB) alone and in combination. Spent Japanese quail carcasses were treated with $5 \%$ GE, $2.5 \%$ $\mathrm{SB}$ and $5 \% \mathrm{GE}+2.5 \% \mathrm{SB}$. Treated spent Japanese quail carcasses were kept at $4 \pm 2{ }^{\circ} \mathrm{C}$ for 12 hours and were evaluated for various physico-chemical and organoleptic qualities. The results showed that spent Japanese quail carcass treated with $5 \% \mathrm{GE}+2.5 \% \mathrm{SB}$ had significantly (P $<0.05)$ better physio- chemical properties as compared to other treated samples. The results of sensory attributes also showed that the scores for appearance and colour, flavour, tenderness, juciness and overall acceptability significantly $(\mathrm{P}<0.05)$ higher for $\% \mathrm{GE}+2.5 \% \mathrm{SB}$ treated spent Japanese quail carcass samples as compared to Japanese quail carcasses treated with $5 \%$ GE or $2.5 \% \mathrm{SB}$. Therefore, combination of $5 \%$ GE and $2.5 \% \mathrm{SB}$ more efficient for tenderization of for spent Japanese quail carcasses for production of products.

KEY WORDS...... Japanese quail, Spent, Ginger extract, Sodium bi carbonate, Tenderization, Quality, Sensory attributes

HOW TO CITE THIS ARTICLE - Anandh, M. Anna (2020). Tenderization of spent japanese quail using ginger extract and sodium bi carbonate. Asian J. Animal Sci., 15(1): 10-14.DOI:10.15740/HAS/ TAJAS/15.1/10-14.Copyright@2020:HindAgri-Horticultural Society.

ARTICLE CHRONICLE - Received : 30.03.2020; Revised : 04.05.2020; Accepted : 19.05.2020 